\title{
Adherence to diabetes guidelines for screening, physical activity and medication and onset of complications and death
}

\author{
Yiqun Chen ${ }^{1,2}$, Frank A. Sloan *, Arseniy P. Yashkin ${ }^{3}$ \\ Department of Economics, Duke University, 213 Social Sciences Building, Box 90097, Durham, NC, 27708
}

\section{A R T I C L E I N F O}

\section{Article history:}

Received 29 May 2015

Received in revised form 30 June 2015

Accepted 1 July 2015

Available online 9 July 2015

\section{Keywords:}

Guidelines

Physical activity

Diabetes complications

Mortality

Health and Retirement Study

\begin{abstract}
A B S T R A C T
Aims: Analyze relationships between adherence to guidelines for diabetes care - regular screening; physical activity; and medication - and diabetes complications and mortality.

Methods: Outcomes were onset of congestive heart failure (CHF), stroke, renal failure, moderate complications of lower extremities, lower-limb amputation, proliferative diabetic retinopathy (PDR), and mortality during follow-up. Participants were persons aged 65+ in the Health and Retirement Study (HRS) 2003 Diabetes Study and had Medicare claims in follow-up period (2004-8).

Results: Adherence to screening recommendations decreased risks of developing $\mathrm{CHF}$ (odds ratio $(\mathrm{OR})=0.83$; $95 \%$ confidence interval $(\mathrm{CI}): 0.72-0.96)$, stroke (OR $=0.80 ; 95 \% \mathrm{CI}$ : 0.68-0.94); renal failure $(\mathrm{OR}=0.82 ; 95 \%$ CI: $0.71-0.95)$; and death ( $\mathrm{OR}=0.86 ; 95 \% \mathrm{CI}: 0.74-0.99)$. Adherence to physical activity recommendation reduced risks of stroke ( $\mathrm{OR}=0.64 ; 95 \% \mathrm{CI}$ : 0.45-0.90), renal failure ( $\mathrm{OR}=0.71 ; 95 \% \mathrm{CI}$ : 0.52-0.97), moderate lower-extremity complications ( $\mathrm{OR}=0.71$; 95\% CI: 0.51-0.99), having a lower limb amputation $(\mathrm{OR}=0.31$, 95\% CI: 0.11-0.85), and death ( $\mathrm{OR}=0.56,95 \% \mathrm{CI}: 0.41-0.77)$. Medication adherence was associated with lower risks of PDR (OR = 0.35, 95\% CI: 0.13-0.93).

Conclusions: Adherence to screening, physical activity and medication guidelines was associated with lower risks of diabetes complications and death. Relative importance of adherence differed among outcome measures.
\end{abstract}

(c) 2015 Elsevier Inc. All rights reserved.

\section{Introduction}

Diabetes mellitus imposes a substantial societal burden. The American Diabetes Association (ADA) estimated that diabetes led to a total cost of $\$ 245$ billion in 2012, including $\$ 176$ billion in direct medical costs and $\$ 69$ billion in reduced productivity (American Diabetes Association, 2013a). As the leading cause of blindness and lower-limb amputations among U.S. adults (Centers for Disease Control and Prevention, 2011), diabetes also has increased the cost to such public programs as Social Security Disability Insurance and Medicaid. One study projected that 1 in 3 U.S. adults could have

Conflict of Interest Statement: This research was supported in part by the National Institute on Aging (grant R01-AG017473). The sponsors had no such involvement in design and conduct of the study, collection, management, analysis, interpretation of the data, preparation, review, approval of the manuscript, writing the report/article, nor the decision to submit the manuscript for publication. Conflicts of interest: none.

* Corresponding author. Tel.: +1 919613 9358; fax: +19196817984.

E-mail addresses: yiqun.chen@duke.edu (Y. Chen), fsloan@duke.edu (F.A. Sloan), arseniy.yashkin@duke.edu (A.P. Yashkin).

1 Tel.: +1 919660 1825; fax: + 19196817984 .

2 Alternative Proof Reader.

3 Tel.: +1919660 1800; fax: +19196817984. diabetes by 2050 if recent increases in diabetes incidence continue (Boyle, Thompson, Gregg, Barker, \& Williamson, 2010), suggesting an even larger burden of diabetes on society in subsequent years.

In an effort to improve diabetes outcomes, the ADA has provided a comprehensive set of guidelines for diabetes care. Although benefits of adherence to guidelines have been documented, most research to date has focused on the association between adherence and glycemic control (Krapek, King, Warren, et al., 2004; Raum, Krämer, Rüter, et al., 2012), followed in order of frequency by health care utilization and costs (Balkrishnan et al., 2003; Wong, Bryson, Hebert, \& Liu, 2014), and quality of life (Martínez, Prado-Aguilar, Rascón-Pacheco, \& Valdivia-Martínez, 2008; Saleh, Mumu, Ara, Hafez, \& Ali, 2014). These studies have generally concluded that there are links between improved adherence and better glycemic control, lower health care utilization and costs, and better quality of life.

Much less attention has been devoted to impacts of adherence to guidelines on onset of diabetes complications and mortality. Persons with diabetes are more likely to experience neuropathic, cardiovascular, nephropathic, and ophthalmic complications that seriously erode quality of life and lead to lost productivity and premature mortality (Bethel, Sloan, Belsky, \& Feinglos, 2007; Boyle et al., 2010). About half of the diabetes treatment costs are attributable to complications (Zhuo, Zhang, \& Hoerger, 2013). The estimated total cost of lost productivity due to diabetes-attributable premature death 
is $\$ 18.5$ billion per year in 2012 (American Diabetes Association, 2013a). Given this substantial financial burden, it is important to investigate potential factors that could prevent diabetes complications and early mortality.

Another limitation of earlier studies is the limited scope of adherence measures-mostly only medication adherence (An \& Nichol, 2013; Gibson, Song, Alemayehu, et al., 2010; Krapek et al., 2004; Raum et al., 2012). Effects of adherence to guidelines for other aspects of diabetes care on diabetes outcomes, and the comparative importance of different adherence, e.g., physical activity adherence and dietary adherence, have not been extensively analyzed.

To overcome these limitations, this study examined 3 measures of adherence in the same study - screening, physical activity, and medication adherence - and their associations with mortality and onset of 5 frequently-occurring complications of diabetes: congestive heart failure (CHF), renal failure, stroke, moderate severity lower-extremity complications, lower-limb amputation, and proliferative diabetic retinopathy (PDR). We limited our analysis sample to individuals aged $65+$, an age group that incurs approximately $60 \%$ of total medical expenditures attributable to diabetes (American Diabetes Association, 2013a). Limiting the study sample to elderly persons allowed us to obtain physician diagnoses of diabetes complications from the Medicare claims files, which should be more reliable than patient self-reports.

\section{Material and methods}

\subsection{Data and subjects}

Data came from the Health and Retirement Study (HRS), the HRS 2003 Diabetes Study (HRS-DM) conducted as a supplement to HRS, 2 other HRS supplemental surveys-the 2005 and 2007 Prescription Drug Study (HRS-DRUG), and Medicare Part A (facility), Part B (professional) and denominator files that contained respondents' dates of death and participation in Medicare Advantage (MA) plans when applicable. Medicare beneficiaries in MA during follow-up were excluded from this study since claims for MA enrollees are not provided on a public use basis. Medicare claims data were merged with interview data from HRS.

The HRS is a biannual longitudinal survey of persons aged 51-61 at study initiation in 1992 and their spouses who could be of any age. The HRS is a nationally representative survey of communitydwelling residents in the U.S. of all race/ethnicities. Individuals in the HRS are followed until death; new replenishment cohorts are added periodically. In 2003, the HRS-DM surveyed HRS respondents who reported a diagnosis of diabetes at the 2002 wave of HRS. Among eligible participants, 1901 returned questionnaires (response rate, $79.7 \%$ ). This survey collected detailed data on patients' treatment and self-management of diabetes not reported in regular HRS interviews which covered a wide range of topics. In 2005 and 2007, another supplemental survey, the HRS-DRUG, was conducted to collect Medicare eligible HRS participants' use of medications. The HRS-DRUG allowed us to supplement respondents' drug use information provided by the HRS-DM. The Medicare claims files contained information on Medicare beneficiaries' medical diagnoses (using the International Classification of Diseases, 9th Revision Clinical Modification (ICD-9-CM)), use of laboratory tests (using Current Procedure Terminology (CPT) codes), and physician visits (as defined by U.S. Centers for Medicare and Medicaid medical specialty codes).

Limiting our analysis sample to persons aged $65+$ in 2003 yielded a sample of 1320 of the total 1901 respondents to the HRS-DM. Individuals not identifiable in Medicare claims files $(n=140)$ or with missing information on any explanatory variable $(n=38)$ were excluded. The final analysis sample consisted of 1142 individuals.
We first identified patients' screening, physical activity and medication information from HRS-DM and HRS-DRUG, and then merged the interview responses to Medicare claims files to obtain dates of diagnosis of diabetes complications and death during the 5 -year follow-up period of 2004-8. The 2002 wave of HRS provided data on respondents' demographic characteristics and income. Since the goal of the analysis was to measure the relationship between adherence to guidelines and onset of complications and death during follow-up, we excluded individuals diagnosed with the complication corresponding to the dependent variable prior to follow-up. Thus, numbers of observations varied by complication.

\subsection{Dependent variables}

Our primary outcomes were physician-diagnosed onset of: (1) congestive heart failure (CHF); (2) stroke; (3) renal failure-a general category encompassing end-stage renal disease, acute renal failure, unspecified renal failure, kidney transplantation, or dialysis; (4) moderate severity complications of the lower extremities-cellulitis, Charcot foot, osteomyelitis, gangrene, diabetic amyotrophy, diabetic neuropathy; (5) serious complications of the lower extremities, measured by having a lower-limb amputation; and (6) proliferative diabetic retinopathy; and (7) death during the 5-year follow up period. The 2 lower-extremity categories were not defined to be mutually exclusive, but few persons fell into both categories. The complication information was identified from the Medicare Part A and Part B claims data using codes from the International Classification of Disease, 9th Revision, Clinical Modification (ICD-9-CM) and Current Procedural Terminology, version 4 (CPT-4) (Table 1). Mortality information was obtained from the Medicare denominator file.

\subsection{Explanatory variables}

Table 1

Diagnosis codes.

\begin{tabular}{|c|c|c|}
\hline Conditions & & Administrative Codes \\
\hline Congestive heart failure $^{a}$ & ICD-9 & $\begin{array}{l}428 . x x 398.91402 .01402 .11 \\
402.91404 .11404 .91\end{array}$ \\
\hline Stroke $\mathrm{a}^{\mathrm{a}}$ & ICD-9 & 431.xx 436.xx 997.02 \\
\hline \multicolumn{3}{|l|}{ Renal failure } \\
\hline Chronic Renal Failure ${ }^{\mathrm{b}}$ & ICD-9 & 585.xx \\
\hline Acute Renal Failure & ICD-9 & 584.xx \\
\hline Unspecified Renal Failure & ICD-9 & $586 . x x$ \\
\hline \multirow[t]{3}{*}{ Transplant } & ICD-9 & V420 \\
\hline & ICD-9(P) & 55.69 \\
\hline & $\mathrm{CPT}$ & 5036050365 \\
\hline \multirow[t]{5}{*}{ Dialysis } & ICD-9 & V45.11 V56.xx \\
\hline & ICD-9(P) & 39.9554 .98 \\
\hline & $\mathrm{CPT}$ & 90921909259096090961 \\
\hline & & 90962909669097090935 \\
\hline & & 909379094590947 \\
\hline \multicolumn{3}{|c|}{ Moderate severity lower extremity complications } \\
\hline Diabetic neuropathy & ICD-9 & 250.6x $357.2355 . x x$ \\
\hline Diabetic amyotrophy & ICD-9 & 358.1 \\
\hline Cellulitis & ICD-9 & $681.1 \times 682.6682 .7$ \\
\hline Charcot foot & ICD-9 & 707.11 \\
\hline Osteomyelitis & ICD-9 & $\begin{array}{l}730.06730 .07730 .16730 .17 \\
730.26730 .27\end{array}$ \\
\hline Gangrene & ICD-9 & $250.7 \times 785.4$ \\
\hline Amputation of lower extremity & ICD-9(P) & $84.1 \mathrm{x}$ \\
\hline Proliferative diabetic retinopathy & ICD-9 & 362.02 \\
\hline \multicolumn{3}{|l|}{ Low cognition } \\
\hline Alzheimer's disease & ICD-9 & $331.0 x 331.1 x 331.2 x 331.9 x$ \\
\hline Senility & ICD-9 & 797.xx \\
\hline Dementia & ICD-9 & 290.xx 294.xx \\
\hline
\end{tabular}

ICD-9: International Classification of Disease, 9th Revision, Clinical Modification; ICD-9(P): ICD-9 for procedure; CPT: Current Procedural Terminology.

a Includes Part A claims only.

b Must be accompanied by dialysis or transplant code, except End Stage Renal Disease (ICD-9: 585.6) introduced in 2005. 
Our choice of screening adherence measures was based on ADA Guidelines (American Diabetes Association, 2013b). Binary variables specified whether an individual obtained the recommended tests in the last year, i.e., lipid test, eye exam, urine analysis and HbA1c test. To generate a single comprehensive measure of screening adherence, we performed a factor analysis on the 4 binary variables and used the first extracted factor (eigenvalue 1.50) that accounted for most of the variation in the 4 variables as a covariate (Table A.1). Higher factor scores indicated it was more likely that the respondent received the tests at the recommended frequency.

For physical activity adherence, following earlier papers (Ainsworth, Haskell, Whitt, et al., 2000; Plotnikoff, Taylor, Wilson, et al., 2006), we considered individuals to be adherent to the physical activity guideline if the person engaged in $600+$ metabolic equivalent tasks/week of moderate or vigorous physical activity (total minutes/ week of moderate activity* $4+$ total minutes/week of vigorous activity*7.5) $\geq 600$ ). Medication adherence was a binary variable, defined as whether the respondents never or rarely (fewer than 1 out of 10 scheduled doses) missed a prescribed dose of oral diabetes medication. We also controlled for whether the respondent was taking oral diabetes medications to account for the fact that some patients were not prescribed such medications. Insulin-use was not accounted in the medication adherence as insulin-users are likely to have more severe diabetes and thus would be more likely to have diabetes complications and premature death in the follow-up period. This could downward-bias our estimations on beneficial effects or even make us find counter-intuitive adverse effects of medication adherence on diabetes outcomes. This concern is supported by our data: we found that insulin-using respondents were more likely to have complications and die in the follow-up period. However, no association between oral diabetes medication use and diabetes complications or premature death was found, thus estimates of effects of medication adherence based on oral medication use would be less subject to bias. To account for the fact that a few oral-medication-taking patients also used insulin, we added a binary variable for whether the patient was using insulin in the regressions. Information on medication adherence came from 2 sources. The primary source was the HRS-DM. When such information was unavailable in HRS-DM, we imputed the value from the HRS-DRUG. Participants in the 2005 HRS-DRUG reporting a $2+$ year length of use and participants in the 2007 HRS-DRUG reporting a $4+$ year length of use were considered to have taken diabetes drugs at baseline (2003).

Other explanatory variables were age, gender, race, marital status, years of schooling completed, household income (in 2002 dollars), whether obese based on the person's body mass index (BMI), total illness burden index (TIBI) score, and low cognition defined as having a diagnosis of Alzheimer's disease, senility, or dementia. The TIBI is a widely used comorbidity measure specifically developed for persons with diabetes (Greenfield, Billimek, \& Kaplan, 2010; Greenfield et al., 1995). The TIBI assesses comorbid illness using self-reported presence and severity of symptoms and conditions in each of 16 body system domains on a scale from 0 to 100. A higher TIBI score indicates worse health. We included the person's TIBI score as a covariate to address the potential concern that persons in worse health and thus at higher risk of future illness and death are more (less) likely to follow care recommendations, which could bias our estimates upward (downward).

We used logistic regression (STATA 11 SE). Duke University's Institutional Review Board approved our study protocol and use of the restricted data prospectively.

\section{Results}

Most respondents had HbA1c tests (78.9\%), lipid tests (59.5\%), urinalysis (75.7\%) and eye exams (70.0\%) in the last year (Table 2). Over half (53.2\%) exercised regularly according to our study criterion; most $(69.3 \%)$ never or rarely missed oral diabetes drugs. These rates
Table 2

Summary statistics $(\mathrm{N}=1142)$.

\begin{tabular}{|c|c|c|c|}
\hline \multicolumn{2}{|l|}{ Variable } & \multirow{2}{*}{$\begin{array}{l}\text { Mean } \\
0.789\end{array}$} & \multirow{2}{*}{$\begin{array}{l}\text { Std. } \\
\text { Dev. } \\
0.406\end{array}$} \\
\hline HbA1c test & $\begin{array}{l}1 \text { if had } 2 \mathrm{HbA} 1 \mathrm{c} \text { tests within the last year, } \\
0 \text { otherwise }\end{array}$ & & \\
\hline Lipid test & $\begin{array}{l}1 \text { if had at least } 1 \text { cholesterol test within } \\
\text { the last year, } 0 \text { otherwise }\end{array}$ & 0.595 & 0.487 \\
\hline Urinalysis & $\begin{array}{l}1 \text { if had at least } 1 \text { urinalysis within the } \\
\text { last year, } 0 \text { otherwise }\end{array}$ & 0.757 & 0.427 \\
\hline Eye exam & $\begin{array}{l}1 \text { if had at least } 1 \text { eye exam within the last } \\
\text { year, } 0 \text { otherwise }\end{array}$ & 0.700 & 0.459 \\
\hline Screening adherence & $\begin{array}{l}\text { Extracted screening adherence score } \\
\text { from factor analysis }\end{array}$ & 0.034 & 0.963 \\
\hline Physical activity & 1 if exercising regularly, 0 otherwise & 0.532 & 0.499 \\
\hline Medication adherence & $\begin{array}{l}1 \text { if never/rarely miss oral diabetes } \\
\text { medication, } 0 \text { otherwise }\end{array}$ & 0.693 & 0.462 \\
\hline Age $65-74$ & 1 if aged $65-74$ & 0.545 & 0.498 \\
\hline Age $75-84$ & 1 if aged $75-84$ & 0.368 & 0.482 \\
\hline Age $85+$ & 1 if aged $85+$ & 0.088 & 0.283 \\
\hline Female & 1 if female, 0 if male & 0.504 & 0.500 \\
\hline Black & 1 if black, 0 otherwise & 0.164 & 0.370 \\
\hline Married & 1 if married, 0 otherwise & 0.604 & 0.489 \\
\hline Education & Years of schooling completed & 11.320 & 3.571 \\
\hline Household income & Unit: $\$ 10,000$ (2002 dollars) & 3.638 & 5.606 \\
\hline TIBI & $\begin{array}{l}\text { Total Illness Burden Index score } \\
\text { (scale: } 0-100 \text { ) }\end{array}$ & 35.138 & 18.359 \\
\hline BMI & Body Mass Index & 29.061 & 5.568 \\
\hline Low cognition & $\begin{array}{l}1 \text { if had Alzheimer's disease, senility, or } \\
\text { dementia }\end{array}$ & 0.055 & 0.228 \\
\hline Insulin & 1 if use insulin, 0 otherwise & 0.238 & 0.426 \\
\hline $\begin{array}{l}\text { Oral diabetes } \\
\text { medications }\end{array}$ & $\begin{array}{l}1 \text { if use oral diabetes medications, } 0 \\
\text { otherwise }\end{array}$ & 0.748 & 0.434 \\
\hline \multicolumn{4}{|c|}{ Baseline conditions (2003) } \\
\hline $\begin{array}{l}\text { Congestive heart } \\
\text { failure }(\mathrm{CHF})\end{array}$ & 1 if had CHF in baseline, 0 otherwise & 0.194 & 0.395 \\
\hline Stroke & 1 if had stroke in baseline, 0 otherwise & 0.088 & 0.283 \\
\hline Renal failure & $\begin{array}{l}1 \text { if had ESRD/acute/unspecified renal } \\
\text { failure/kidney transplantation/dialysis in } \\
\text { baseline, } 0 \text { otherwise }\end{array}$ & 0.053 & 0.223 \\
\hline $\begin{array}{l}\text { Lower extremity } \\
\text { complications }\end{array}$ & $\begin{array}{l}1 \text { if had moderate severity lower } \\
\text { extremity complications in baseline, } \\
0 \text { otherwise }\end{array}$ & 0.406 & 0.491 \\
\hline Amputation & $\begin{array}{l}1 \text { if had amputation in baseline, } 0 \\
\text { otherwise }\end{array}$ & 0.008 & 0.088 \\
\hline $\begin{array}{l}\text { Proliferative diabetic } \\
\text { retinopathy(PDR) }\end{array}$ & 1 if had PDR in baseline, 0 otherwise & 0.025 & 0.157 \\
\hline \multicolumn{4}{|c|}{ Follow up period (2004-2008) } \\
\hline $\mathrm{CHF}$ & $\begin{array}{l}1 \text { if diagnosed with CHF in 2004-2008, } \\
0 \text { otherwise }\end{array}$ & 0.417 & 0.493 \\
\hline Stroke & $\begin{array}{l}1 \text { if diagnosed with stroke in } 2004-2008 \text {, } \\
0 \text { otherwise }\end{array}$ & 0.215 & 0.411 \\
\hline Renal failure & $\begin{array}{l}1 \text { if diagnosed with ESRD/acute/ } \\
\text { unspecified renal failure/kidney } \\
\text { transplantation/dialysis in 2004-2008, } \\
0 \text { otherwise }\end{array}$ & 0.252 & 0.434 \\
\hline $\begin{array}{l}\text { Lower extremity } \\
\text { complications }\end{array}$ & $\begin{array}{l}1 \text { if diagnosed with moderate severity } \\
\text { lower extremity complications in 2004- } \\
2008,0 \text { otherwise }\end{array}$ & 0.615 & 0.487 \\
\hline Amputation & $\begin{array}{l}1 \text { if had amputation in } 2004-2008,0 \\
\text { otherwise }\end{array}$ & 0.019 & 0.138 \\
\hline $\begin{array}{l}\text { Proliferative diabetic } \\
\text { retinopathy(PDR) }\end{array}$ & $\begin{array}{l}1 \text { if diagnosed with PDR in 2004-2008, } 0 \\
\text { otherwise }\end{array}$ & 0.053 & 0.223 \\
\hline Death & 1 if died in 2004-2008, 0 otherwise & 0.279 & 0.449 \\
\hline
\end{tabular}

Note: ESRD = End Stage Renal Disease.

are slightly higher than those reported in earlier studies that focused on younger samples (Bayer et al., 2014; Feil, Zhu, \& Sultzer, 2012).

Of the total study sample, $50.4 \%$ were female, $16.4 \%$ were black, and $60.4 \%$ were married. Most were aged $65-84$. Mean educational attainment, household income, BMI and TIBI score were 11.3 years, $\$ 36,380$, 29.1, and 35.1, respectively. Most sample persons (74.8\%) used oral diabetes medications; many fewer used insulin (23.8\%). 
Relative to the baseline, substantial proportions of respondents were diagnosed with complications during follow-up: CHF (22.3\%); moderate lower extremity complications (20.9\%); renal failure (19.9\%); and stroke (12.7\%). Fewer persons were diagnosed with PDR $(2.8 \%)$ or had lower-limb amputations $(1.1 \%)$.

Adherence to ADA screening recommendations for screening tests at baseline year decreased the probability of being diagnosed with CHF (odds ratio $(\mathrm{OR})=0.83$; $95 \%$ confidence interval $(\mathrm{CI})$ : 0.72 $0.96)$, stroke ( $\mathrm{OR}=0.80 ; 95 \% \mathrm{CI}$ : $0.68-0.94)$; renal failure $(\mathrm{OR}=0$. 82; 95\% CI: 0.71-0.95); and death (OR $=0.86$; 95\% CI: 0.74-0.99) (Table 3). As the covariate for screening adherence was measured by a factor score from the factor analysis, to interpret the findings, we compared the 10th percentile of the factor score for adherence screening to the score at the 90th percentile of scores. Comparing screening adherence at the 10th percentile of the sample, at which point persons only received HbA1c tests (Table A.1), to the 90th percentile of the sample, where individuals received all 4 recommended tests-HbA1c tests, eye exams, urinalysis, and lipid tests, the probability of developing CHF during follow-up fell by 0.42 . The corresponding reductions for stroke were 0.50 , for renal failure, 0.68 , and death, 0.61 .

Relationships between adherence to the physical activity recommendations and outcomes during follow-up were similarly strong, although there were differences in outcomes for which adherence was statistically significant and in the magnitudes of the reductions in the odds of adverse outcomes. Adherence to such recommendations reduced the probability of being diagnosed with stroke $(\mathrm{OR}=0.64$; 95\% CI: $0.45-0.90$ ), renal failure ( $\mathrm{OR}=0.71 ; 95 \% \mathrm{CI}: 0.52-0.97$ ), moderate lower-extremity complications ( $\mathrm{OR}=0.71$; $95 \% \mathrm{CI}$ : $0.51-$ 0.99), having a lower limb amputation ( $\mathrm{OR}=0.31,95 \% \mathrm{CI}: 0.11-$ $0.85)$, and death ( $\mathrm{OR}=0.56,95 \% \mathrm{CI}$ : $0.41-0.77)$ during follow-up. Fewer of the results for medication adherence were statistically significant. Such adherence was negatively associated with the probability of developing PDR (OR $=0.35,95 \%$ CI: 0.13-0.93).

Overall, older age, a higher TIBI score, lower cognition, and being obese were associated with increased odds of complications and mortality (not shown). The sample sizes varied among regressions since we excluded persons who had the complication at baseline. The most common complication at baseline was for moderate lower-extremity complications.

Persons who died during follow-up were included in the analysis of complications' onset. A potential concern is that death is a competing risk to complications' onset. If death occurs during follow-up, persons may die before complications' onset, thus biasing the estimated beneficial effects of adherence downward if decedents were relatively less likely to be adherent to guidelines and conversely if the odds of complications' onset is increased immediately before death.
Table A.1

Distribution of scores for factor 1 from factor analysis and percentages of persons with tests.

\begin{tabular}{llllll}
\hline Percentiles & Score & HbA1c (\%) & Lipid test (\%) & Urinalysis (\%) & Eye exam (\%) \\
\hline 10 & -1.423 & 100 & 0 & 0 & 0 \\
25 & -0.623 & 100 & 100 & 0 & 0 \\
50 & 0.262 & 100 & 0 & 100 & 100 \\
75 & 1.062 & 100 & 100 & 100 & 100 \\
90 & 1.062 & 100 & 100 & 100 & 100 \\
\hline
\end{tabular}

Note: numbers in column 3 to 6 mean percentages of patients had HbA1c tests, lipid tests, eye exams and urinalyses in the last year, respectively, for all patients with each of the factor score reported in column 2 .

In our analysis sample, individuals who died during follow-up were more likely to have been diagnosed with the study complications beforehand. In the subsample of persons who died during follow-up, $61.8 \%$ were diagnosed with CHF, and $32.6 \%$ and $43.9 \%$ were diagnosed with stroke and renal failure prior to death, respectively. The corresponding percentages of diagnoses among persons who did not die during follow-up were about half as large: $33.9 \%, 17.1 \%$, and $18.0 \%$, respectively. When we added death during follow-up as a covariate to our analysis of complications' diagnosis, the parameter estimate on this covariate generally indicated that diagnosis was more likely. Results on adherence were not materially affected (results not shown). Thus, if anything, the results presented above underestimate the importance of adherence to guidelines.

\section{Discussion}

Our results show that adherence to ADA recommendations often was followed by reduced risks of diabetes complications and death, but there were differences in the relationship between adherence and specific outcomes according to the type of adherence. Better adherence to recommended screenings was associated with lower risks of being diagnosed with CHF, renal failure, and stroke and death during follow up among persons diagnosed with diabetes at baseline. Physical activity adherence was related to reduced risks of stroke, renal failure, moderate and serious severity lower-extremity complications, and death. For medication adherence, statistically significant association between medication adherence and lower rates of PDR was also observed. While most attention in studying adherence has been devoted to drugs designed to treat diabetes, the evidence presented in this study demonstrates that adherence to screening and physical activity guidelines is at least as important in delaying a range of diabetes complications and death.

Our estimates are comparable to a few existing studies evaluating the link between diabetes medication adherence and complication

Table 3

Logistic regression results.

\begin{tabular}{|c|c|c|c|c|c|c|c|}
\hline Variables & $\mathrm{CHF}$ & Stroke & Renal & Lower extremity & Amputation & PDR & Death \\
\hline \multirow[t]{2}{*}{ Screening adherence } & $0.827 *$ & $0.801^{* *}$ & $0.822^{* *}$ & 0.926 & 1.178 & 1.150 & 0.855* \\
\hline & {$[0.715,0.957]$} & {$[0.680,0.942]$} & {$[0.709,0.952]$} & {$[0.785,1.094]$} & {$[0.748,1.853]$} & {$[0.829,1.594]$} & {$[0.741,0.987]$} \\
\hline \multirow[t]{2}{*}{ Physical activity } & 0.783 & $0.637^{* *}$ & 0.706* & $0.711 *$ & $0.311 *$ & 0.781 & $0.564 * *$ \\
\hline & {$[0.576,1.065]$} & {$[0.451,0.898]$} & {$[0.517,0.965]$} & {$[0.509,0.994]$} & {$[0.114,0.850]$} & {$[0.391,1.561]$} & {$[0.414,0.769]$} \\
\hline Medication & 0.778 & 1.265 & 0.869 & 0.895 & 0.382 & 0.348 & 0.809 \\
\hline Adherence & {$[0.411,1.473]$} & {$[0.602,2.658]$} & {$[0.460,1.643]$} & {$[0.476,1.682]$} & {$[0.074,1.959]$} & {$[0.130,0.934]$} & {$[0.441,1.486]$} \\
\hline Observations & 921 & 1,042 & 1,082 & 678 & 1,133 & 1,113 & 1,142 \\
\hline
\end{tabular}

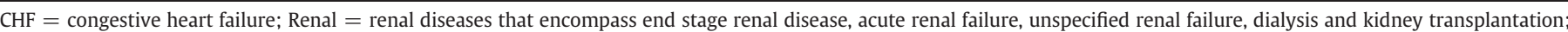

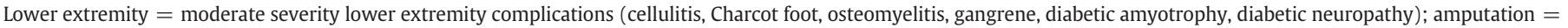
lower-limb amputation; PDR = proliferative diabetic retinopathy.

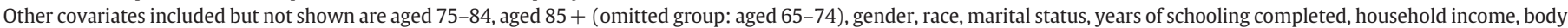
mass index, total illness burden index score, low cognition (had Alzheimer's disease, senility, or dementia), whether use insulin, and whether use oral diabetes medications. $95 \%$ confidence intervals in brackets.

Boldfaced indicates statistical significance.

* $\mathrm{p}<0.05$.

** $\mathrm{p}<0.01$. 
outcomes and death. Using data on elderly individuals, Kuo et al. (2003) concluded that persons with diabetes with poor consistency in use of diabetes medications (inconsistent use or discontinuation of drugs in follow-up surveys) were $43 \%$ more likely to die over a 7 -year period compared with patients who used medications consistently, an effect size somewhat larger than the one we reported. No significant association between diabetes medication adherence and risk of circulation problems was observed, a result consistent with our study. Another study documented that adherence to diabetic medications is associated with lower rates of retinopathy (Gibson et al., 2010), which is consistent with our results. Based on a sample of employees diagnosed with diabetes, Bayer et al. (2014) concluded that patients who received regular screenings for lipids, microalbuminuria tests and HbA1c measurements experienced decreased risks of complications compared to those who received less complete testing, with a hazard rate (HR) of 0.39 for congestive heart failure and 0.49 for renal disease, both results indicating higher effect sizes than the ones we obtained.

The effects of physical activity in reducing diabetes-complication risk factors such as dyslipidemia, dysglycemia, hypertension and excess weight in persons diagnosed with diabetes have been well documented in earlier literature (Agosti, Graziano, Artiaco, \& Sorrentino, 2009; Herbst, Kordonouri, Schwab, Schmidt, \& Holl, 2007; Kirk, Mutrie, MacIntyre, \& Fisher, 2003). For example, Boulé, Haddad, Kenny, Wells, and Sigal (2001) found that an 8-week duration of exercise training on patients with type 2 diabetes reduced HbA1c levels by $0.66 \%$ on average, an amount equivalent to a reduction of the risk of microvascular complication of $24.4 \%$ (Stratton et al., 2000) and cerebrovascular diseases by $11.9 \%$ (Selvin et al., 2004). Blomster et al. (2013) found that diabetes patients who report moderate to vigorous activity were $15 \%$ less likely to experience microvascular events and $17 \%$ less likely to die when compared to persons with diabetes who undertook no or only mild physical activity. All these studies suggest potential benefits of adherence to physical activity requirements on reducing risks of diabetes-associated complications and mortality, which are confirmed by our study results.

We found no significant link between physical activity and a diagnosis of PDR during follow-up. Regular physical activity may reduce the risk of PDR through its beneficial effects on blood pressure and high-density lipoprotein cholesterol, but earlier studies have also found that physical activity has no effect on PDR (Cruickshanks, Moss, Klein, \& Klein, 1992; Kriska, LaPorte, Patrick, Kuller, \& Orchard, 1991), possibly because physical activity is a relatively unimportant factor in the etiology of PDR (Cruickshanks et al., 1992).

Our study has several important strengths. First, we focused on the understudied link between adherence and onset of diabetes complications and death. Many studies have reported a significant association between adherence to guidelines for care of diabetes and patient outcomes including glycemic control, health care utilization, expenditures on personal health care services, and quality of life (Balkrishnan et al., 2003; Krapek et al., 2004; Martínez et al., 2008; Raum et al., 2012; Saleh et al., 2014; Wong et al., 2014). However, much less attention has been paid to effects of adherence on diabetes complications and mortality. Second, in contrast to most earlier studies that have focused on a limited scope of adherence measures, mainly only medication adherence, we used a more comprehensive set of adherence measures. This allowed us to compare the relative importance of different types of adherence.

We acknowledge these study limitations. First, the HRS-DM survey from which most of our data were obtained only contains 1901 observations. After exclusions, the analysis sample fell to 1142 for deaths and even less for analysis of outcomes conditional on not having the study complication at baseline. Second, we were unable to document the reasons for non-use of diabetic drugs, which could reflect either a lack of clinical indicators for use not observed in our data or adverse side effects of these drugs experienced by patients. Third, we did not include measures of adherence to other lifestyle activities such as diet, smoking and drinking. Diet information, although provided by the HRS-DM, are not sufficiently detailed to permit construction of a valid measure. Smoking and excess alcohol consumption, 2 other behaviors associated with recommended diabetes self-care, were too low in the sample to permit meaningful inference. Fourth, since we excluded persons with diabetes who had the study complications at baseline except for the mortality analysis, the remaining persons in our analysis could have been healthier than elderly persons with a diabetes mellitus diagnosis as a whole. However, we controlled for TIBI, a widely used health measure for diabetes patients, which could mitigate such concern to some extent. Fifth, we do not account for patients' use of routine diabetes care, a potential determinant of diabetes outcomes, but our measure of screening test adherence should reflect use of routine diabetes care since patients typically obtain tests at physician visits or immediately prior to such visits. Also, controlling for patients' socio-demographic characteristics, which are proxies to individuals' access to and use of medical care, in the estimation could help mitigate concerns on this limitation.

These limitations notwithstanding, our results underscore the importance of improving adherence to screening tests which in turn permits timely administration of effective therapeutic interventions, as well as self-care measured in terms of physical activity and medication use. At least half of cost of diabetes treatment is attributable to its complications (American Diabetes Association, 2013a; Brown, Pedula, \& Bakst, 1999). The lost productivity due to diabetes-attributed premature mortality had led to a total cost of $\$ 18.5$ billion per year in 2012 (American Diabetes Association, 2013a). Given this high cost, even only a modest reduction in rates of diabetes complications and premature death is causally associated with better adherence to care recommendations; there would be a wide margin for benefits by driving improvement in this realm.

\section{Financial disclosure}

No financial disclosures were reported by the authors of this paper.

\section{Acknowledgments}

This research was supported in part by the National Institute on Aging (grant R01-AG017473). The sponsors had no role in design and conduct of the study, collection, management, analysis, interpretation of the data, preparation, review, approval of the manuscript, or decision to submit the manuscript for publication. There is no conflict of interest to be reported. No financial disclosures were reported by the authors of this paper. All three authors were involved in the conception and design of the study, data analysis and interpretation, wrote and revised the paper, and approved the final version of the submitted manuscript.

\section{References}

Agosti, V., Graziano, S., Artiaco, L., \& Sorrentino, G. (2009). Biological mechanisms of stroke prevention by physical activity in type 2 diabetes. Acta Neurologica Scandinavica, 119(4), 213-223.

Ainsworth, B. E., Haskell, W. L., Whitt, M. C., Irwin, M. L., Swartz, A. M., Strath, S. J., et al. (2000). Compendium of physical activities: An update of activity codes and MET intensities. Medicine and Science in Sports and Exercise, 32(9; SUPP/1), S498-S504.

American Diabetes Association (2013a). Economic costs of diabetes in the US in 2012 Diabetes Care, 36(4), 1033-1046.

American Diabetes Association (2013b). Standards of medical care in diabetes-2013. Diabetes Care, 36(Suppl. 1), S11-S66.

An, J., \& Nichol, M. B. (2013). Multiple medication adherence and its effect on clinical outcomes among patients with comorbid type 2 diabetes and hypertension. Medical Care, 51(10), 879-887.

Balkrishnan, R., Rajagopalan, R., Camacho, F. T., Huston, S. A., Murray, F. T., \& Anderson, R. T. (2003). Predictors of medication adherence and associated health care costs in 
an older population with type 2 diabetes mellitus: A longitudinal cohort study. Clinical Therapeutics, 25(11), 2958-2971.

Bayer, F. J., Galusha, D., Slade, M., Chu, I. M., Taiwo, O., \& Cullen, M. R. (2014). Process of care compliance is associated with fewer diabetes complications. The American Journal of Managed Care, 20(1), 41-52.

Bethel, M. A., Sloan, F. A., Belsky, D., \& Feinglos, M. N. (2007). Longitudinal incidence and prevalence of adverse outcomes of diabetes mellitus in elderly patients. Archives of Internal Medicine, 167(9), 921-927.

Blomster, J. I., Chow, C. K., Zoungas, S., Woodard, M., Patel, A., Poulter, N. R., et al. (2013). The influence of physical activity on vascular complications and mortality in patients with type 2 diabetes mellitus. Diabetes, Obesity and Metabolism, 15(11), 1008-1012.

Boulé, N. G., Haddad, E., Kenny, G. P., Wells, G. A., \& Sigal, R. J. (2001). Effects of exercise on glycemic control and body mass in type 2 diabetes mellitus: A meta-analysis of controlled clinical trials. The Journal of the American Medical Assocaition, 286(10), $1218-1227$.

Boyle, J. P., Thompson, T. J., Gregg, E. W., Barker, L. E., \& Williamson, D. F. (2010). Projection of the year 2050 burden of diabetes in the US adult population: Dynamic modeling of incidence, mortality, and prediabetes prevalence. Population Health Metrics, 8(1), 29-40.

Brown, J. B., Pedula, K. L., \& Bakst, A. W. (1999). The progressive cost of complications in type 2 diabetes mellitus. Archives of Internal Medicine, 159(16), 1873-1880.

Centers for Disease Control and Prevention (2011). National diabetes fact sheet: National estimates and general information on diabetes and prediabetes in the United States, 2011. Atlanta, GA: US Department of Health and Human Services, Centers for Disease Control and Prevention.

Cruickshanks, K. J., Moss, S. E., Klein, R., \& Klein, B. E. (1992). Physical activity and proliferative retinopathy in people diagnosed with diabetes before age $30 \mathrm{yr}$. Diabetes Care, 15(10), 1267-1272.

Feil, D. G., Zhu, C. W., \& Sultzer, D. L. (2012). The relationship between cognitive impairment and diabetes self-management in a population-based community sample of older adults with type 2 diabetes. Journal of Behavioral Medicine, 35(2), 190-199.

Gibson, T. B., Song X. Alemayehu, B., Wang S. S., Waddell, J. L., Bouchard, J. R., et al. (2010). Cost sharing, adherence, and health outcomes in patients with diabetes. The American Journal of Managed Care, 16(8), 589-600.

Greenfield, S., Billimek, J., \& Kaplan, S. (2010). The total illness burden index. In V. Preedy, \& R. Watson (Eds.), Handbook of disease burdens and quality of life measures (pp. 73-85). New York: Springer.

Greenfield, S., Sullivan, L., Dukes, K. A., Silliman, R., D'Agostino, R., \& Kaplan, S. H. (1995). Development and testing of a new measure of case mix for use in office practice. Medical Care, 33(4), AS47-AS55.
Herbst, A., Kordonouri, O., Schwab, K. O., Schmidt, F., \& Holl, R. W. (2007). Impact of physical activity on cardiovascular risk factors in children with type 1 diabetes: A multicenter study of 23,251 patients. Diabetes Care, 30(8), 2098-2100.

Kirk, A., Mutrie, N., MacIntyre, P., \& Fisher, M. (2003). Increasing physical activity in people with type 2 diabetes. Diabetes Care, 26(4), 1186-1192.

Krapek, K., King, K., Warren, S. S., George, K. G., Caputo, D. A., Mihelich, K., et al. (2004). Medication adherence and associated hemoglobin A1c in type 2 diabetes. Annals of Pharmacotherapy, 38(9), 1357-1362.

Kriska, A. M. LaPorte, R. E. Patrick, S. L, Kuller, L. H., \& Orchard, T. J. (1991). The association of physical activity and diabetic complications in individuals with insulin-dependent diabetes mellitus: The Epidemiology of Diabetes Complications Study-VII. Journal of Clinical Epidemiology, 44(11), 1207-1214.

Kuo, Y. -F., Raji, M. A., Markides, K. S., Ray, L. A., Espino, D. V., \& Goodwin, J. S. (2003), Inconsistent use of diabetes medications, diabetes complications, and mortality in older Mexican Americans over a 7-year period data from the Hispanic established population for the epidemiologic study of the elderly. Diabetes Care, 26(11), 3054-3060.

Martínez, Y. V., Prado-Aguilar, C. A., Rascón-Pacheco, R. A., \& Valdivia-Martínez, J. J. (2008). Quality of life associated with treatment adherence in patients with type 2 diabetes: A cross-sectional study. BMC Health Services Research, 8(1), 164-173.

Plotnikoff, R. C., Taylor, L. M., Wilson, P. M., Courneya, K. S., Sigal, R. J., Birkett, N., et al. (2006). Factors associated with physical activity in Canadian adults with diabetes. Medicine and Science in Sports and Exercise, 38(8), 1526-1534.

Raum, E., Krämer, H. U., Rüter, G., Rothenbacher, D., Rosemann, T., Szecsenyi, J., et al. (2012). Medication non-adherence and poor glycaemic control in patients with type 2 diabetes mellitus. Diabetes Research and Clinical Practice, 97(3), 377-384.

Saleh, F., Mumu, S. J., Ara, F., Hafez, M. A., \& Ali, L. (2014). Non-adherence to self-care practices \& medication and health related quality of life among patients with type 2 diabetes: A cross-sectional study. BMC Public Health, 14(1), 431-438.

Selvin, E., Marinopoulos, S., Berkenblit, G., Rami, T., Brancati, F. L., Powe, N. R., et al. (2004). Meta-analysis: Glycosylated hemoglobin and cardiovascular disease in diabetes mellitus. Annals of Internal Medicine, 141(6), 421-431.

Stratton, I. M., Adler, A. I., Neil, H. A. W., Matthews, D. R., Manley, S. E., Cull, C. A., et al. (2000). Association of glycaemia with macrovascular and microvascular complications of type 2 diabetes (UKPDS 35): Prospective observational study. BMJ Clinical Research, 321(7258), 405-412.

Wong, E. S., Bryson, C. L., Hebert, P. L., \& Liu, C. -F. (2014). Estimating the impact of oral diabetes medication adherence on medical costs in VA. Annals of Pharmacotherapy, 48(8), 978-985.

Zhuo, X., Zhang, P., \& Hoerger, T. J. (2013). Lifetime direct medical costs of treating type 2 diabetes and diabetic complications. American Journal of Preventive Medicine, 45(3), 253-261. 